\title{
O discurso do "combate às drogas" e suas ideologias
}

\author{
The discourse of the "fight against drugs" and its ideologies
}

\author{
Richard Bucher*, Sandra R.M. Oliveira**
}

\begin{abstract}
BUCHER, R. \& OLIVEIRA, S.R.M. O discurso do "combate às drogas"e suas ideologias. Rev. Saúcle Pública, 28: 137-45, 1994. À luz de considemções científicas sobre o abuso de drogas, discute-se a ideologia dos textos sobre drogas que seguem uma orientação moralista e repressora, a despeito das condições sócio-históricas do consumo. Colocam-se cm foco os sentidos não-literais para situar tais discursos no contexto da sua produção e para detectar neles formas de manutenção de poder presentes nas relações sociais. Utiliza-se a teoria da análise do discurso como a metodologia apropriada para se desvendar os indicadores da idcologia que impõe aos textos sobre drogas uma determinada modalidade. Os resultados revclam um discurso com propósitos claramente persuasivos, direcionando e manipulando modos de ser e de ver na sociedade, deixando-se interpretar como parte interessada em um pesado sistema de conformismo social. Conclui-se que a questão das drogas não é tratacla em si, mas enquanto mito construído, usado para combater série de desvios da ordem social vigente.
\end{abstract}

Descritores: Abuso de substâncias, prevenção. Linguagem. Autoritarismo.

\section{Considerações sobre o discurso do "combate às drogas"}

Entre as diversas abordagens da "questão das drogas", nas sociedades modernas, destacase aquela que enfatiza o "combate às drogas", apresentando-o como a única maneira capaz de enfrentar e erradicar o "grave flagelo". De expressão rigorosamente condenatória, caracteriza-se pela veemência de uma argumentação mais emotiva e alarmista do que serena e objetiva, mais sensacionalista do que científica, mais moralista do que isenta de juízos valorativos. Desta forma, incita a uma "cruzada anti-drogas", cuja beligerância encobre série de fatores que, de certo, contribuem decisivamente para a expansão do fenômeno.

Portanto, ao invés de analisar o consumo de drogas em seus múltiplos determinantes para chegar a propostas preventivas pertinentes $\mathrm{e}$ prometedoras de eficácia, tal abordagem limitase a preconizar uma repressão implacável, restringindo-se, desta forma, às drogas ilicitas. Ora,

\footnotetext{
- Departamento de Psicologia Clínica da Universidade de Brasília - Brasília, DF - Brasil

* Bolsista junto ao Departamento de Psicologia Clínica da Universidade de Brasília - Brasília, DF - Brasil

Separata/Reprints: R. Bucher - PCL-UnB - 70910-900 - Brasília, DF - Brasil
}

em muitos países, entre os quais o Brasil, são precisamente as substâncias lícitas as mais consumidas e as mais fortes geradoras de abusos e dependências. Trata-se aí de um fato epidemiológico inconteste, a ser levado a sério diante da distorção do fenômeno introduzida pela pregação tantas vezes piegas do "combate às drogas". Opor-se a esta visão reducionista não significa, no cntanto, entregar-se à apologia do consumo de substâncias psicoativas, mas tão somente defender uma análise objetiva e contextualizada da situação das drogas em uma determinada sociedade. Não se trata, pois, da defesa de uma posição extremista de "liberação de todas as drogas"para um consumo indiscriminado, mas do respeito por uma experiência humana milenar, a ser examinada numa linha histórico-antropológica para que se torne possivel apreender suas significações modernas.

Constata-se, de fato, que a cegueira da posicão repressiva radical traz mais estragos do que benefícios, por fazer prevalecer uma visão unidimensional, inapropriada para o trato do fenômeno em toda sua complexidade. As numerosas implicações ideológicas daquela visão não encontram o necessário contra-peso através de análises sociais profundas, pertinentes e abrangentes (Carlini - Cotrim \& Pinski ${ }^{3}$, 1989).

$\Lambda$ bordar a "questão das drogas" no enfoque combativo citado significa, ainda, não tratá-la 
como realidade a ser investigada, mas sim, tiansformá-la em mito fabricado para cumprir determinadas funções sociais. Espalhada no bojo da "cruzada anti-drogas", lhe é imputada nitidatmente a função de "bode expiatório", fazendo-a aparecer como responsível por grande parte dos revezes sociais; produz-se então una mistificação, erigindo-se uma cortina de fumaça ao redor do pretendido "flagelo", o que impede seu dimensionamento correto c averigüável, imprescindivel para se ultrapissar o nivel de preconceitos, prejulgamentos e visões preconcebidas, ou ainda, aquele de interpretações unidirecionais ou tendenciosas (Bucher ${ }^{2}, 1992$ ).

Qualquer discurso que enfoca questões sociais pode, conforme os seus cifitos de scntido, transformar ou manipular as representações coletivas com a finalidade de manter certas estruturas de poder; da mesma forma, pode modificá-las, visando à superaçãa dessas mesmas cstruturas. Assim, adquirem identidade particular, aparecendo como formações que se definem pelos senticlos ideológicos que reiteram c que vão direcionar a sua função cnunciativa. Desencaleadas a partir da interação de opiniões diferentes sobre questões de interesse comum, tais formações apresentam regularidades $\mathrm{cm}$ seu funcionamento que permitem interpretátas como parte de uma matriz ideológica especíli$\mathrm{ca}$, constituindo o que se denomina, $\mathrm{cm}$ Análise do Discurso, de formação discursiva.

Aplicando esta concepção à discussão sobre drogas, pode-se formular a hipótese scgundo a qual determinados textos, ainda que produzidos em setores diferentes, constituem uma mesma formação discursiva, promovendo a circulação de uma série de senticlos específicos. Estes, no seu conjunto, incorporam toda uma ideologia anti-drogas, plataforma para se clivulgarem e implantarem mediclas de controle daqueles fenômenos de consumo considerados, no referido prisma ideológico, como socialmente indesejáveis e portanto, exigindo repressĩo (Oliveira $^{10}, 1992$ ).

A partir dessas considerações, propõe-se um recorte no extenso campo de produção sobre drogas, submetendo à análise a formação discursiva do "combate", buscando compreender os seus processos de significação e a forma como influem na construção do senso comum do brasileiro a respeito da temática $\mathrm{cm}$ paula, incluinclo aí as repercussõcs no campo da saúde pública.

A aproximação dá-se através do conceito de ideologia, enfatizada enquanto categoria explicaliva do funcionamento dos discursos sociais. Lim lace deste termo controverso e plurívoco, lançou-se mão do discernimento de polariclacles positiva e negativa para incluir seus inúmeros significados em dois registros: o descritivo ce o crílico. O primeiro enfoque refere-se a sistemas de pensamentos, crenças, valores ou "cosmovisão"; por sua vez, o sentido crítico aponta as idéias e atitudes postas ao serviço da sustcntação das relações assimétricas de poder, da injustiça social e da distribuição desigual de dircilos e rendas.

lixplotam-se, assim, as rclações cntre idcologia c linguagcm, ultrapassando a noção de linguagem como sistcma de comunicação para corrclacionátia com os fenômenos conflitantes da cstruturação social da qual cla própria faz parte. Dessa mancira concebida, a linguagem passa a ser definida como discurso, ou seja, como ato social ou ação que visa a produzir cficitos (Tiorin ${ }^{5}, 1990$ ).

Se é verdade que nenhum discurso escapa do envolvimento com a dimensĩo ideológica, discernir os dois cnfoques citados propicia uma avaliação contingente dos cfeitos de sentido dominantes, permitindo compreender o alcance de determinato fenômeno social, no caso, o consumo de drogas. Assim, uma contextualização desse consumo como fenômeno histórico e antropologicamente situado permite apreender descritivamente seus sistcmas de valores, crenças e representações populares, enquanto que uma análise crítica clas produções sobre drogas, proferidas por certas instâncias de poder ou de autoridade, permite detectar tendências, esforços e manipulações para proteger detcrminadas relações econômicas e políticas vigentes.

É com este intuito de avaliação clílica que textos representativos do discurso repressivo sobre drogas foram analisados no presente trabalho. Ao visar as cocrções institucionais que marcam tal produção discursiva, levantaram-se questões vinculadas ao poder institucional, às práticas repressivas, punitivas $c$ assistenciais em saúde mental, aos jogos de interesses políticos e econômicos no comércio de drogas lícitas 
(além das ilícitas), ao papel do profissional nas áreas de saúde, educação, ação social, justiça e pesquisa científica.

Dentre as numerosas contradições possíveis de se apontar na formação discursiva da "cruzada anti-droga" destacaram-se certos pressupostos inerentes à sua vinculação com as estruturas sociais e de poder que as engendram e que asseguram sua divulgação - pressupostos esses detentoras de configurações ideológicas, cujos contornos mais precisos tentou-se apreender.

\section{Método: Ideologia e análise do discurso}

$\mathrm{Na}$ investigação proposta, optou-se pela Análise do Discurso como instrumento adequado para examinar a ligação entre a linguagem apresentada e a ideologia subjacente. Sua metodologia permite explicitar os processos comunicativos construídos nos textos sobre drogas e detectar intenções secretas ou interesses escusos em veicular idéias condenatórias radicais, por razões que ultrapassam os efeitos nefastos do consumo de drogas em si.

A Teoria do Discurso apóia-se no conceito de linguagem como sendo a materialidade apropriada à ideologia. Sistematizada inicialmente por Pecheux ${ }^{12}$, (1969), a Análise do Discurso, somada à contribuição de autores como Bakhtin ${ }^{1}$ (1970), Foucault ${ }^{7,8}$ $(1969,1971)$, Ducrot ${ }^{4},(1972)$ e Fairclough ${ }^{6}$, (1989), vem sendo amplamente utilizada para trabalhar os sentidos não literais dos enunciados, com base no reconhecimento da dimensão sócio-histórica da linguagem.

Na sua origem, a Teoria da Análise do Discurso, tal como idealizada por Pecheux ${ }^{12}$, aparece ligada à dimensão político-ideológica: suas premissas básicas apoiam-se na concepção da linguagem ter um modo de constituição profundamente histórico, não sendo possível dissociá-lo do conjunto das práticas humanas. Por esta razão, saber quem fala, para quem fala, em que situação, de que lugar da sociedade, com que intento, são elementos de suma importância no processo comunicativo.

$\mathrm{Na}$ constituição dos signifícados manifestam-se as coerções ideológicas que incidem sobre a linguagem. Nas chamadas ordens do dis- curso (Foucault ${ }^{8}, 1971$ ) expressam-se determinadas condições sócio-históricas que impregnam as formações discursivas, enquanto conjunto de regras limitadas no tempo e no espaço e que definem as condições de exercício da funçĩo enunciativa. Os discursos que reiteram processos socialmente cristalizados podem ser apreendidos como partes de uma mesma matriz, determinando regularidades definidas pela rclação que mantêm com a ideologia.

Tais idéias chaves servem para a compreensão da ideologia e das injunções de poder no discurso repressivo sobre drogas. Repertoriando esse discurso no espaço específico onde se articulam linguagem e icleologia, é possivel ressaltar os processos de significação que regem o imaginário social sobre drogas no Brasil. Para tanto, série de características linguísticas relativas ao vocabulário e à gramática são consideradas marcas para o entendimento analítico de tais processos. O presente trabalho, no entanto, não se limita à análise da superfície linguística, mas examina também as propriedades discursivas que se situam alćm das marcas formais.

Examinando-se a rclação do texto com o discurso e com o contexto, atingem-se três nivcis de análise, conforme três níveis de organização: a situação social do momento imediato, a instituição social enquanto matriz do discurso, o nível mais amplo da socicdade como um todo e das suas ideologias. O procedimento completo da análise passa pelas etapas da descrição, interpretação e explicação (segundo Fairclough 9, abrangendo vocabulário, gramática e estrutura textual, visando a revelar tanto os esquemas classificatórios quanto as combinações das formas linguísticas.

$\mathrm{Na}$ análise contextual do discurso repressivo sobre drogas aparece como particularmente relevante para a apreensão dos sentidos implícitos o exame dos pressupostos e dos subentendidos. Estes se deixam considerar como estratégias linguísticas e rctóricas para neutralizar possíveis conseqüências de uma compreensão literal dos atos da fala. Assim, querendo dizer mais do que se diz ou apagando sentidos pelo silenciamento de aspectos cruciais do consumo de drogas, é possível produzir representações convenientes a uma determinada formação social. $O$ não-dito, por exemplo, sob a vertente do implícito (diz " $x$ " querendo dizer " $y$ ") e aquela do 
anti-implícito (diz " $\mathrm{x}$ " querendo silenciar " $\mathrm{y}$ "), pode determinar certas significações ocultadas no discurso "oficial" (Orlandi $\left.{ }^{4}, 1990\right)$ ).

A fim de clarear a trama discursiva que sustenta a idéia do "combate às drogas" e apontar os elementos usados para dirigir a opinião pública rumo ao entendimento "certo" da questão, são colocadas na base da investigação perguntas como: que elementos são articulados para se chegar a uma representação ideologicamente orientada da droga? que dados são silenciados, quais outros superdimensionados? que relações de poder estão em jogo...?

\section{Material: Os textos analisados}

Foi desenvolvida uma análise prévia de um conjunto de textos sobre drogas, lançando-se mão de uma leitura assistemática que acabou determinando a composição do corpus. Os textos foram selecionados pelas especificidades e regularidades discursivas correspondendo ìs características da formação impregnada pelo Leitmotiv do "combate às drogas". Assim, a recorrência de determinadas particularidades linguísticas, retóricas e temáticas serviu para diferenciar e agrupar os textos como partes de um mesmo processo de divulgação idcológica.

Na presente análise destacaram-se as seguintes características, induzindo à escolha das unidades de pesquisa e das categorias de referência:

1. Silenciamento acerca das questões sociais que concorrem para os fenômenos de uso, abuso e dependência de drogas.

2. Desconsideração da motivação do usuário, da sua dimensão subjetiva.

3. Simplificação do fenômeno das drogas, apontando elementos unidimensionais na etiologia da dependência.

4. Centralização exclusiva no produto tóxico (ilícito).

5. Tratamento genérico dos efeitos da droga, pela lei do tudo ou nada, sem especificação do produto, do padrão de uso, da personalidade e história de vida do usuário, do contexto.

6. Associação dramática freqüente entre droga e sexo, droga e crime, droga e loucura, droga e morte.

7. Omissão do fato de que a droga pode propiciar prazer, sensações agradáveis, facilidades de comunicação e relaxamento.

8. Omissão ou descaso a respeito do uso e abuso de medicamentos psicotrópicos e outras drogas lícitas.

9. Crença na intervenção heróica e desinteressada que livrará a comunidade e o país, definitivamente, das drogas.

10. Recomendação de atividades religiosas, morais, patrióticas e esportivas como estratégias de prevenção (ou mesmo como "vacinas").

De acordo com a prevalência desses temas, foram feitos cortes $\mathrm{cm}$ três instâncias de produções discursivas: textos amcricanos divulgados no Brasil, documentos oficiais brasileiros e textos da imprensa brasilcira. Os textos sclecionados para a análise foram:

Documentos de produção americana:

a) O Presidente Bush adverte estudantes sobre o consumo de drogas. Brasília, Embaixada Amcricana. Tradução do documento editado pelo USIS - United Stales Information Service, 1989;

b) Escola sem drogas. Brasília, Embaixada Americana. Tradução do documento editado pclo US Department of Education, 1989; Documentação oficial brasileira:

c) PREVIDA - Programa de Prevenção, Educação e Vida: subsídios para o clucador. Brasília, CONEN/DF, 1991;

d) MURAD, J.E.: Como manter sua escola longe das drogas. Belo Horizonte, ABRAÇO/PREVID $\Lambda^{*}, 1989$;

Produçãojornalística:

e) Império do pó. Jornal do Brasil, 26/02/92, p. 10 ;

f) Na cartcira ao lado. VTJA, 27/03/91, p. 42-48.

Com base na interpretação e explicação dos elementos linguísticos, da estrutura argumentativa e dos implícitos desses textos, foi possível apreender os elementos cruciais da ideologia que formenta a sua produção e os sustenta.

\section{Resultados da análise: 0 "combate às drogas" como construção ideológica}

Os resultados demonstram que há série de regulariclades discursivas comuns aos textos ana-

ABRAÇO - Associação Comunitária de Pais e Mestres para Prevenção ao Abuso de Drogas.

PREVIDA - Programa de Prevenção, Educação e Vida. 
lisados (e a muitos outros sobre o assunto, $\mathrm{cm}$ particular na imprensa cotidiana) que se ligam entre si, cooperando na fixação de sentidos ideologicamente comprometidos. Estes, por sua vez, propiciam práticas que atendem às necessidades de controle social e de manutenção de certos padrões da ordem vigente.

Os textos remelem-nos a uma visão preconceituosa, repressora e, por vezes, moralista, obtendo aceitação nos segmentos políticos e públicos que se destacam seja pelo desconhecimento do tema, seja pelas tendências conservadoras ou anti-liberais. O autoritarismo e a monossemia são marcas que dirccionam suas operações verbais, dirigidas aos leitores com objetivos claramente persuasivos, visando a exercer inlluência decisiva sobre as suas representações - como, de fato, qualquer discurso de propaganda ou de publicidade. $\Lambda$ s produções funcionam então como cúmplices nas explicações e justificações dessa visão preconccbida da questão das drogas.

Pode-se concluir que os textos analisaclos fazem parte de um grande conjunto denominado formação discursiva anti-drogas. Encuanto entidade global, ela é abstrata c inacessível, mas se deixa conhecer através clos textos particulares dando corpo material ao seu funcionamento.

Enumeram-se, em seguida, os principais efeitos de sentido construídos neste discurso, detectados pela análise praticada.

1. Segundo sua retórica argumentativa, destaca-se como primcira função a meta da persuasão. Termos expressivos e combinações lingüísticas diversas estão voltados para a construção de um sentido dominante. Palavras carregadas de conteúdos ameaçaclores como sinistro, luta, guerra, espúrio, crime, morte e outros, são usadas com frequência, ajudancio a construir enunciados de teor passional, o que dificulta uma avaliação sóbria da problemática.

Outros recursos, como a reiteração e o argumento de autoridade, capazes de promover o discurso como consensual, colaboram para levar o sujeito a aderir à concepção proposta. Por exemplo, enunciados do tipo: "O Presidente Bush deu uma lição aos estudantes norte-americanos sobre responsabilidadc e maturidade"(texto a, p.1), introduzem personagens importantes como estratégia de valorização da mensagem. É o chamado argumen- to de autoridade, que fortalce o efeito persuasivo na medicla do prestígio que se associar ao lugar de fala do orador - no caso, o Presidente dos EUA.

Exercem também lunção decisiva, pois criam um "efeito verdade", os números e os dados estatísticos freqüentemente apresentados scm citar a fonte. É comum a referência a númcros de grande porte, de forma a alarmar mais do que informar, como ilustra o seguinte exemplo: "Pesquisas mostram que o uso de drogas entre as crianças é dez vezes mais prevalente do que os pais suspeitam" (b, p.2).

Vê-se, pois, mensagens que não lêm por objetivo informar, mas convencer, limitando a possibilidade de claboração de uma concepção própria por parte do leitor. É clessa forma que se constrói o discurso do consenso, pelo qual transmitem-se idćias como partilhadas virtualmente por todos, investindo-as do papel de um axioma do qual não se pode (ou deve) duvidar. Assim sendo, os textos induzem uma verdadeira subordinação intelectual: o lcitor mergulha no movimento de "combate às drogas" sem se dar conta, uma vez que cste ć apresentado (se não apregoado) como único caminho para enfrentar e "resolver" a questĩo do consumo.

2. O tom autoritário e alarmista imprimido aos textos que materializam o discurso $\mathrm{cm}$ pauta traz como resultado a idéia de um saber único e exclusivo. $\Lambda$ tendência de se apresentar como detentor da verdade está então duplamente presente: pelo carátcr formal da produção mas também pela força dos argumentos veiculados. O discurso autoritário é o campo da certeza, do imperativo categórico que manifesta um saber supremo, levando o interlocutor a aceitá-lo como verdade. Impedc-se, por conseguinte, a expansĩo de um pensamento mais crítico, seja indiviclual, scja social ou comunitário.

Uma das maneiras pelas quais os produtores de lextos consegucm impor os scus argumentos dáse com a utilização de verbos como tenho encontrado, estou convencido, acredito, precisamos, que exprimem uma atitude de convicção, marcanclo a posição autoritária do locutor.

Reforça tal análise a presença de termos como trinchcira, combate, perigoso, danoso, insinuanclo guerra e sofrimento. Lstas são associadas às drogas para provocar um clima de repúdio incondicional, subsidiando enuncia- 
dos do tipo: "O consumo de drogas não é um fato novo na história da humaniclade, atualmente observa-se um incremento crescente do seu consumo, gerando grandes problemas sociais e de saúde como a violência, a marginalidacke, a prostituição, a auto-destruição e morte". (c, p. 15).

O enunciado acima usa o recurso linguístico denominado de paralelismo, que repete uma certa estrutura para reforçar uma idćia, acentuando o seu efeito (a violência, a marginalidade, a prostituição, a auto-destruição e morte). Faz dessa forma emergir o sentido de que a droga é hoje o único fator causal de problemas que, por outras razões, sempre estiveram presentes na história da humanidade.

3. Uma das técnicas fundamentais na construção do discurso anti-droga são os silenciamentos, utilizados seja para omitir deliberadamente algo, seja para fala supcrficialmente de um fato que poderia enfraquecer a argumentação. Assim, fala-se muito da droga ilícita omitindo-se falar das drogas lícilas - as mais consumidas no mundo inteiro e as mais perniciosas para a saúde pública. Aplica-se indiscriminadamente o termo droga, induzindo o leitor a incluir nesta categoria apenas os produtos ilícitos, pela associação permanente com palavras como tráfico, posse, busca, apreensĩo, aplicação da lei, notificação e oultras, termos que exclucm qualquer possibilidade de vínculo com a substância alcoólica ou outro produto legalmente aceito.

Assim, no enunciado: "(...) apelou para que tomassem parte na luta contra os narcóti$\cos ^{\prime \prime}(\mathrm{a}, \mathrm{p} .1)$, o termo luta, pela sua associação com narcóticos, faz referência ao narcotráfico; somado à ausência de informações sobre contexto, tipo e padrão de uso do produto, determina a inclusão de todas as drogas em uma mesma categoria e reduz a uma única forma de consumo toda a gama de possibilidades de uso - desde o consumo ocasional ou recreativo até o dependente.

Em que pesem referências ocasionais ao consumo de álcool, fumo, psicofärmacos e solventes, o efeito de sentido criado é de que só a droga ilegal "é problema". Transmitindo-se a idéia de que existem duas categorias de substâncias, as perigosas (= ilegais) e outras benignas, beneficia-se implicitamente a inclústria farmacêutica e o comércio das substâncias lícitas.
4. Uma outra idéia chave diz respcito à apresentação do cidadão, em particular jovem, como ser indefeso, necessitando de orientação e proteção: "O nosso papel é fazer prevenção e tentar ajudar os alunos que caem nessa" (f, p.46). Ou ainda: "Precisamos continuar a propiciar apoio e orientação aos jovens para que façam escolhas sãs." (b, p.VD). Enfatiza-se dessa forma o relacionamento vertical (provedor/receptor) ou ainda paternalista, articulado à perfecição com o modclo da socicdade disciplinar, cuja racionalidade estimula o controle institucional, a relação autoritária, o enquadramento dos indivíduos sem participação criativa, sem responsabiliclade civil e sem pensamento crítico.

No parigrafo "Se as bocas funcionam nos morros, administradas por traficantes que aterrorizam comunidades indefesas, explorando e pervertendo menores, os consumidores proliferam em loclas as camadas sociais" (e, p.10), vê-se da mesma forma a construção de sujcitos sociais frágeis, olários ou vitimados. Note-se o vocábulo indefesas, modificando radicalmente o termo comuniclade, transmitinclo a idéia de inércia, passividade, vulncrabilidade. Embora na perspectiva sociológica o termo comunidade caracterize um agrupamento com forte cocsão afetiva, com capacidade de organização ativa e transformadora, prevalece no texto o sentido de fragilidade e sujeição.

Insistindo sobre a passividade como inevitável - implicanclo em negar qualquer possibiliclade de atutonomia pessoal - incentiva-se como cfeito adicional toda uma desmobilização social. É como se, diante da "ameaça das drogas", o cidadão, "por sua ingenuidade e incapacidade de defesa", precisasse da intervenção reguladora das autoridades benevolentes e "competentes". Desta forma, ilustra-se (c estimula-se) a longa trajetória da submissão obediente às normas disciplinares, rumo à construção de "corpos dóccis" (Foucault? , 1975).

5. Outra característica marcante dos textos analisados diz respeito àquelas construções sobre drogas que as apresentam como um mal em $\mathrm{si}$, independentemente do uso que delas se faz, das ações subjetivas e dos processos sociais. Utilizando os recursos lingüísticos de personalização, nominalização, metáforas, apresentam-se os fenômenos como desvinculados de outros fatores que intcrvêm na dinâmica dos 
comportamentos de consumo.

Os enunciados abaixo exemplificam a personificação, figura de linguagem pela qual os seres inanimados agem como se fossem pessoas. Aplicada à droga, empresta-lhe vida e ação, impedindo que fosse percebida como parte de um processo social: "As drogas ameaçam a vida de nossos filhos, causam ruptura em nossas escolas e desagregam famílias" (b, p.41). Ou: "Não existe a escola onde a droga não entra" (f, p.43).

Apaga-se assim a subordinação do consumo de drogas às dinâmicas social $\mathrm{e}$ individual, necessárias à sua configuração como "problema". Eventos sociais, historicidade, motivações e decisões pessoais são negligenciados em bcnefício de determinadas lógicas simplistas que, "inexistentes" por não serem diretamente explicitadas nos textos, não podem ser contestados - tão pouco que as formas de controle social que encetam.

Na sociedade atual, a individualidade incomoda. Desta forma, ela é submetida a um mecanismo disciplinar que a vilipendia como "desvio da norma", para que se possa assegurar a homogeneização das multipliciclades humanas. Necessitando de um campo social homogêneo, os poderes hegemônicos - políticos mas sobretudo econômicos - não conseguem conviver com as diferenças, marcando-as enfaticamente para poder normatizá-las. Mas eis o paradoxo: com a coerção normalizadora, a diferença se acentua e faz o sujeito aparecer como desviante (Velho ${ }^{13}, 1978$ ).

6. Outro sentido prevalente refere-se a uma visão do mundo simplista e maniqueista. Seus autores, referenciados por ideologias repressoras e moralistas, enveredem então com facilidade pelo campo do dogmatismo absoluto, considerando a verdade como propriedade pessoal. Usam verbos na forma imperativa e termos como jamais, nunca, que insinuam uma posição de certeza, de verdade, de supremacia das afirmações expressas:

"Ensine aos seus filhos desde criança a dizer não" ... "Mostre-lhes que o uso de drogas é perigoso"... "Jamais permitam que os filhos menores façam uso de bebidas alcoólicas"(d, p.8).

Tais enunciados ensinam e ordenam com tamanha convicção que não resta ao leitor senão acatar e submeter-se à força da argumentação construída no texto. Simultancamente, são evitados os advérbios modalizadores possivelmente, provavelmente, ou verbos no futuro do pretérito, o que revela o postulado de uma visão transparente da realidade.

Prevalccem então os verbos na forma presente, atestando significados absolutos, verdades incontestáveis que não necessitam de interpretação: "O uso ocasional de drogas é responsável pelas vítimas na guerra das drogas"(a, p.1); "as instituições, principalmente a família, estão sofrendo uma de suas piorcs crises" (c, p.15); "o traficante cstá na sala de aula sentado na carteira ao lado do estudante, a quem irá oferecer maconha ou cocaína" (f, p.43).

Com a separação maniquéista do mundo $\mathrm{cm}$ dois blocos compactos e inconciliáveis - o mundo dos bons e o mundo dos maus, ao exemplo das fábulas de mocinhos e bandidos os autores de tais textos legitimam os próprios papéis: protetores dos "bons cidadãos", cujos comportamentos correspondem às expectativas de "normalidade", e perseguidores dos "viciados e traficantes" e outros desviantes de normas, cujos comportamentos são incriminados de ameaçarem a "ordem social".

Vilipendiando representantes de diferenças como desviantes, cria-se todo um sistema de acusação, podendo funcionar como estratégia valiosa para a manutenção de certos poderes discriminatórios. São acusações que, uma vez formalizadas, implicam um claborado ritual de exorcização - segundo o exemplo bem conhecido do bode cxpiatório - envolvendo todo um aparato institucional respaldado pela lei, isto é, pela possibilidade de cocrção e punição.

"Viciado", em particular, contém toda uma acusação moral que assume explicitamente uma dimensão policial e política. Implicitamente, carrega uma acusação totalizadora pondo em dúvida não apenas a cicladania, mas a própria humanidade do usuário de drogas. Rotulado como "maconheiro" ou "marginal", passa a ser visto como alguém que atenta contra a moral e os bons costumes, mas também contra as próprias instituições, o que faz dele um ser anti-social. Vítimas de uma tal estigmatização, os drogaditos são considerados como "desviantes" e transformam-se, a partir daí, em excluídos da convivência social pacífica, em fúnção de princípios rígidos, impostos, mantidos e manipulados ideologicamente. 


\section{Conclusão: "Combate às drogas" para quê?}

As análises dos mecanismos de poder envolvidos no discurso de "combale às drogas" indicam formas de um processo disciplinar referentes a um contexto autoritário, discriminatório e repressivo. Seus textos contribuem com o trabatho político (senão policial) de sujcição do cidadão a um determinado ideário de harmonia social, ajudando a encobrir as contradições inerentes às sociedades modernas e sustentando relações de força estabelecidas entre certos grupos sociais. Ele contrasta em particular com a abordagem do "problema das drogas" que o situa no âmbito da saúde pública, enquanto ameaça não à "ordem social", mas à saúde da população no sentido amplo, visando em particular os danos causados pelos abusos de álcool e fumo.

O discurso em pauta não se constitui, portanto, como uma simples idéia, um conhecimento objetivo e benéfico ou uma idealidade discursiva sobre drogas e seus inegáveis malelicios. Sua ação mais eficaz consiste no papel de disciplinarização das pessoas, na medicla em que compactua com normas de concluta constitutivas de um amplo projeto normalizador das relações sociais. Apontando a possibilidade e a ameaça de condutas desviantes, funda-se a prescrição normativa que desencadeia o controle, a intervenção e a exclusão.

Reproduz-se assim, a cada instante, as condições de possibilidades de implantação, na sociedade, de uma estratégia de normalização fundada numa razão a parentemente concreta e irrefutável: o indivícluo social recluzido à sua condição de usuário ou dependente de drogas - reduzido, em suma, a ser um "viciado" em função de um não conformismo qualquer.

Dessa forma, as justificativas, explicações, recomendações e argumentos que o discurso de "combate às drogas" usa ou inventa para desestimular o consumo, devem ser entendidos menos em razão do próprio fenômeno e mais em função das estruturas de poder e do sistema de normas dominantes que impõem a supremacia da ordem moral, social e econômica vigente.

Em suma, esta formação discursiva apresenta-se como uma abordagem unilateral e restritiva, de natureza persuasiva, que fortalece posições radicais contra ustúrios e dependentes. Além-se, fundamentalmente, ì propagação de duas metas: por um lado, veicular explicações e recomcndações que garantam a adaptaç̃̃o dos cidadĩos à ordcm social, conccbida como entidade ahistórica, inquestionável, imutável c ideal; por outro, a de prover intervenções repressoras e punitivas que excluem o sujeito diferente, apontado como uma ameaça às instituições c à socicdade como um todo.

A dimensão ideológica permcia o conjunto desses textos, vinculando suas formas e idćias a sistemas de poder presentes nas relações sociais, necessitando de controles eficazes. Eticamente descompromissado com o ser humano e sua existência, constrói um quaciro de moralismo que se baséia na intolcrância quanto à pluralidade das opções e visões; por não se fundar numa ética humanista, torna-se incapaz de caminhar em direção a valores representativos de liberdade e dignidade, estcios de uma convivência democrálica se não harmoniosa, pelo menos norteacla pelos ideais de justiça e respeito às diferenças.

O modelo repressivo apregoado pelo discurso anti-droga deve ser questionado não apenas pela sua comprovada incficácia $\mathrm{cm}$ diminuir o consumo de drogas e cm contribuir significativamente para resolver as questões de saúde pública que levanta, mas por impor um sistema de intervenção injusto e freqüentemente desumano. Obcecados pela idćia de combater as drogas ilícitas por mecanismos jurídicos e policialis - o que significa, de fato, redução da problemática social e sanitarista do abuso de drogas ao combate ao narcotrálico - os adeptos deste discurso esquecem-se da dimensão humana, bem como da necessidade de modelos de prevenção e tratamento que valorizem a vida e a pessoa, dentro de um contexto abrangente de cologia humana.

Esquecem-se, ainda, de que não existe nenhuma razão, nem fillosófica, nem farmacológica, nem antropológica, nem alopata, nom ho. meopala, de se posicionar "contra" as drogas, visto que essas são neutras em si c que eventuais problemas decorrem das condições de consumo adotadas por cleterminados sujeitos; esquecem-se, afinal, que "scr do contra" raramente representa uma contribuição construtiva, mas sim, uma postura defensiva, em prol, por exem- 
plo, mais do "status quo" do que das mudanças estruturais necessárias para que as sociedades se tornem menos desequilibradas e injustas.

A idéia do "contra" merece uma última análise: até que ponto o discurso anti-droga não satisfaz a uma antiga, mas sempre viva necessidade dos detentores de poder, aquela de precisar de um inimigo - se não cxtcrno, então interno à socicdade...?Afinal, a atual onda de intolerância diante das drogas iniciou-se nos Estados Unidos após a derrota no Victnam, onde os narcóticos, em particular os opiáceos, tinham um papel não desprezível, devidamente apontado pelos defensores da glória militar americana. A potencialidadc "explicativa" da inculpação das substâncias psicoativas ilícitas foi sem dúvida realçada com o desa parecimento do grande inimigo externo, o comunismo e seus poderes militares.

O embate belicista deslocou-se, desde então, de preferência para o plano do narcotráfi$\mathrm{co}$, inimigo econômico poderoso, bem organizado e bem protegiclo, superado pelos mercados do petróleo e dos armamentos, mas capaz de desestabilizar as economias de mercado ocidentais pela instalação de poderes paralelos. Esta nova vertente da ameaça às hegemonias estabelecidas no ocidente suscitou colossatis estratégias de combate transferidas de outros campos de batalha - com certeza não pelo perigo das drogas em si, mas pelo envolvimento macro-econômico que as caracteriza.

Eis talvez um outro sentido, e não dos mais inocentes, da dimensão ideológica detectada no discurso de combate às drogas. Pcla sua prevalência no setor das políticas públicas, o ser humano mais uma vez sai perdendo, descartado que é diante de interesses apresentados como superiores àqueles da saúde pública, senão como "suprahumanos". Fica a questão, inquietante, de saber quem seria, afinal, o verdadeiro inimigo do homem - este sim a scr investido, no interesse da humanidade e dos direitos do homem, como alvo de um combate mais nobre e mais ético do que aquele dirigido, aparentemente, às drogas e aos seus mitos.

BUCHER, R. \& OLIVEIRA, S. R. M. [The discourse of the "fight against drugs" and its ideologies]. Rev. Saílde Pública, 28: 137 -45, 1994. The ideological contents of the literature on drug consumption and addiction with a moralistic and cnforcement approach are analysed from a scicntilic and public health point of view. A non-literal sense is brought out so that the discourse may be understood in its original context and its links with the forms of power present in social relations. The theory of discourse analysis is used as the appropriate methodology by which the ideological indicators that impose on the texts on diugs a predetermined bias are to be found. The results clearly reveal a persuasive discourse that has the propose of directing and manipulating ways of being and sceing in society, allowing the authors to be seen as interested parties in a heavy-handed system for the maintenance "of the social status quo". The conclusion is that in these tests, it is not really the drug question in itsclf that is dealt with, but rather a mythical construction, used do combat social deviation.

Keyzuords: Substance abuse, prevention and control. Language. Authoritarianism.

\section{Referências Bibliográficas}

1. BAKII'TIN, M. Problemas cla poética de Dostoieviski. Rio de Janeiro, Forense - Universitária, 1981.

2. BUCIIER, R. Dirogas e alrogadição no Brasil. Porto Alcgre, Artes Médicas 1992.

3. CARLINI-COTIRIN, B. \& PINSKI, I. Prevenção ao abuso de drogas na escola: uma revisĩo da literatura internacional recente. Cacl. Pesq, 69: 48-52, 1989.

4. DUCRO'T, O. Principios de semântica lingüística. São Paulo, Cultrix, 1988 (Original: 1972).

5. HIORIN, J.L. Linguagem e icleologia. São Paulo, Ática, 1990.

6. TMIRCLOUGH,N. Linguage and power: London, Lougman, 1989.

7. FOUCAULT, M. A arqueologia do saber. Rio de Janeiro, Forense-Universitária, 1987. (Original: 1969).

8. FOUCAULT, M. L'ortire du discou's. Paris, Gallimard, 1971.

9. FoUCAULT, M. Vigiar e punir. Petrópolis, Vozes, 1988. (Original: 1975).

10. OLIVEIRA, S.R.M. Idcologia no discurso sobre as drogas. Brasília, 1992 [Disscrtação de Mestrado - Universidade de Brailial.

11. ORNALDI, E.P. Terra à vista: discurso do confronto: velho e novo mundo. Campinas, Cortez, 1990.

12. PIsCIIEUX, M. Analy'se antomatique du discours. Paris, Dunod, 1969.

13. VELIIO, G. Duas categorias de acusação na cultura brasileira contemporînea. In: Figucira, S. coord.Sociedade e doença mental. Rio die Janciro, Campus, 1978. p. 37-45.

Recebido para publicação em 12.4.1993 Reapresentado em 24.11.1993

Aprovado para publicação em 7.3.1994 